\title{
Erratum to: Non-reproductive triggers of postpartum psychosis
}

\author{
Ian Brockington ${ }^{1}$
}

Published online: 5 December 2016

(C) Springer-Verlag Wien 2016

\section{Erratum to: Arch Womens Ment Health}

DOI:10.1007/s00737-016-0674-9

In the section headed 'Thyrotoxicosis', the first sentence should read, 'Graves' disease is occasionally associated with acute psychosis, as shown by at least nine case reports and Brownlie's survey in New Zealand'. The words, 'Note that this patient had myxoedema' belong to the second case report, 3 paragraphs lower down, which should end 'With thyroxin and risperidone she recovered within six days. Note that this patient had myxoedema'.

The online version of the original article can be found at: http://dx.doi. org/10.1007/s00737-016-0674-9

$\triangle$ Ian Brockington

i.f.brockington@bham.ac.uk

1 University of Birmingham, Edgbaston, Birmingham HR7 4TE, UK 